\title{
Peer-instruction Usando Ferramentas On-line
}

Bruno Sanches de Lima e Carlos Alberto Moreira dos Santos*

Escola de Engenharia de Lorena da Universidade de São Paulo

* Autor para correspondência: cams@demar.eel.usp.br

\section{RESUMO}

Peer-instruction é uma metodologia ativa de ensino-aprendizagem que auxilia professores a quantificar, em tempo real, a compreensão e o entendimento dos tópicos ministrados em sala de aula. Instituições que desejam adequar suas salas de aula com vistas à aplicação desse método devem investir em um sistema eletrônico capaz de coletar as respostas de cada estudante quando uma questão de múltipla escolha é lançada pelo professor. Este trabalho mostra que não é só possível, mas também vantajoso o uso do peer-instruction sem a compra e a instalação de sistemas eletrônicos complexos por meio da utilização apenas de uma conexão de internet sem fio, smartphones ou laptops, algumas ferramentas on-line e redes sociais.

Palavras-chave: Peer-instruction; Metodologias Ativas de Ensino-Aprendizagem; Interação Socioconstrutivista a Longa Distância; Interdisciplinaridade.

\begin{abstract}
Peer-instruction is an active and interactive learning methodology that helps teachers to quantify the level of comprehension of the subjects presented during class. Institutions that wish to apply this method have to invest in classrooms that have an electronic system capable of collecting each student's answer when a multiple choice question is made by the teacher. This work shows that is not only possible but also beneficial use the Peer-Instruction methodology without further investments or purchase of complex electronic apparatus by only having a wireless internet connection available to the students, smartphones or laptops, some free online tools, and social networks.
\end{abstract}

Keywords: Peer-Instruction; Active Learning Methods; Socio Constructivism Interaction at Long Distances; Interdisciplinary.

\section{Introdução}

Não há dúvidas de que o peer-instruction (PI) é uma das mais importantes metodologias ativas de ensino-aprendizagem para estimular estudantes e obter feedback em tempo real com grande precisão acerca do aprendizado sobre um determinado tópico exposto durante uma aula. Para a aplicação do PI no modelo considerado tradicional, faz-se necessário adaptar uma sala de aula com um sistema que tanto permita a discentes enviarem suas respostas quanto possibilite ao professor acessar e quantificar tais respostas em tempo real (CROUCH \& MAZUR, 2001). Hoje existem empresas especializadas na adequação de salas de aula a esse tipo de sistema, comumente chamado de clickers (LASRY, 2008), cujos custos de instalação podem chegar a trinta dólares por estudante.
Mais especificamente, os clickers consistem em um pequeno controle remoto que possuibotões com as letras "a", "b", "c" e "d" de modo que cada letra representa uma alternativa de resposta para uma pergunta de múltipla escolha. Uma versão antiga do PI usa cartões de papel com letras (MOURA, 2016), enquanto uma versão atual do sistema utiliza um aplicativo vinculado a smartphones, mas continua associado a interesses comerciais ${ }^{1}$.

Atualmente, o Brasil detém o quarto maior mercado de celulares e smartphones do mundo ${ }^{2}$, de tal forma que $26 \%$ da população brasileira têm acesso a smartphones, o que, naturalmente, torna tal dispositivo muito comum entre os estudantes do ensino superior. Além disso, a grande maioria das universidades brasileiras disponibiliza acesso à internet por meio de links sem fio (wireless), algo 
que permite à quase totalidade dos estudantes dessas instituições desfrutar de acesso à internet, em suas mãos, praticamente sem custos.

Diante de tais fatos, alguns questionamentos têm sido objeto de controvérsia entre professores, dentre os quais emergem as seguintes questões: a internet e os smartphones ou laptops podem contribuir positivamente com aulas expositivas? Se sim, de que maneira? Apesar de toda a discussão acerca do benefício ou não do acesso à internet durante aulas, muitos professores já têm lançado mão dessa ferramenta para tentar aprimorar sua atividade docente por meio do uso de vídeos, exemplos reais e/ou ferramentas interativas. Muito embora diversos professores ainda não aceitem o uso da internet durante suas aulas, vários outros sugerem que o emprego dela e das redes sociais diminui a distância na interação professor-aluno.

Adicionalmente às questões mencionadas anteriormente, existe um ponto que deve ser cuidadosamente considerado, que é a habilidade que cada professor possui quando se trata do uso de novas Tecnologias de Informação e Comunicação (TIC) em sala de aula. É sabido que muitos docentes possuem certa dificuldade em lidar com dispositivos eletrônicos e os aplicativos destes, especialmente com aquelas ferramentas de última geração, enquanto os estudantes, em geral muito mais novos, ao contrário, além de possuírem facilidade com elas, são cada vez mais estimulados pela pressão social e interesse comercial a consumirem-nas. Tal fato tem colocado os profissionais de ensino em uma situação delicada, pois acaba por causar um distanciamento cada vez maior entre professor e aluno.

Nesse sentido, o desenvolvimento de ferramentas mais simples e interativas para professores e alunos apresenta-se como um dos desafios para profissionais da área de ensino e da educação, algo que se insere no contexto das dificuldades para a realização de atividades interdisciplinares (FAZENDA, 2001). É provável que as novas gerações superem esse desafio com certa facilidade, uma vez que é próprio dos estudantes de hoje lidarem intuitivamente com tal problema.
Este trabalho lida com as questões apresentadas acima e reporta uma maneira de se utilizarem ferramentas on-line ditas gratuitas (disponíveis aos alunos e professores sem custo durante as aulas), demonstrando que smartphones ou laptops podem facilmente substituir os clickers na metodologia PI. Assim, o PI foi adaptado para que redes sociais e outras ferramentas on-line pudessem ser utilizadas durante as aulas. A técnica adaptada permite que não só testes de múltipla escolha sejam utilizados, mas também questões discursivas. $\mathrm{O}$ trabalho foi realizado no período de 2013 a 2015 em disciplinas de Física I e II dos cursos de engenharia da Escola de Engenharia de Lorena (EEL). Para demonstrar a eficácia e simplicidade do PI adaptado com ferramentas on-line, reportam-se exemplos apresentados em tempo real durante a exposição deste trabalho no $1^{\circ}$ Congresso de Graduação da Universidade de São Paulo (2015).

\section{A Experiência na Escola de Engenharia de Lorena}

A Figura 1 apresenta um fluxograma detalhado sobre a aplicação do PI. Quadros em verde representam passos fundamentais para o emprego do PI no seu modelo considerado tradicional (MAZUR, 2013). Quadros em laranja expõem os passos adicionais que auxiliam e aumentam a eficácia do método. O quadro em amarelo representa o ponto chave deste trabalho.

Como se considera que as etapas do PI são autoexplicativas (quadros em verdes), elas não serão descritas neste trabalho [para mais detalhes do funcionamento do PI tradicional, vide MAZUR (2013)].

Com relação aos passos adicionais (quadros em laranja), podem-se mencionar os seguintes aspectos: a criação de questões conceituais em disciplinas mais básicas como física e matemática sempre enfrenta o desafio de estas não serem atrativas para os estudantes devido à distância inerente entre os conceitos abordados e a realidade dos graduandos (muitas vezes, os alunos consideram as disciplinas abstratas e complexas). Assim, mesmo com a existência de inúmeros livros-texto que auxiliam essas disciplinas, ainda assim apenas adotá-los 


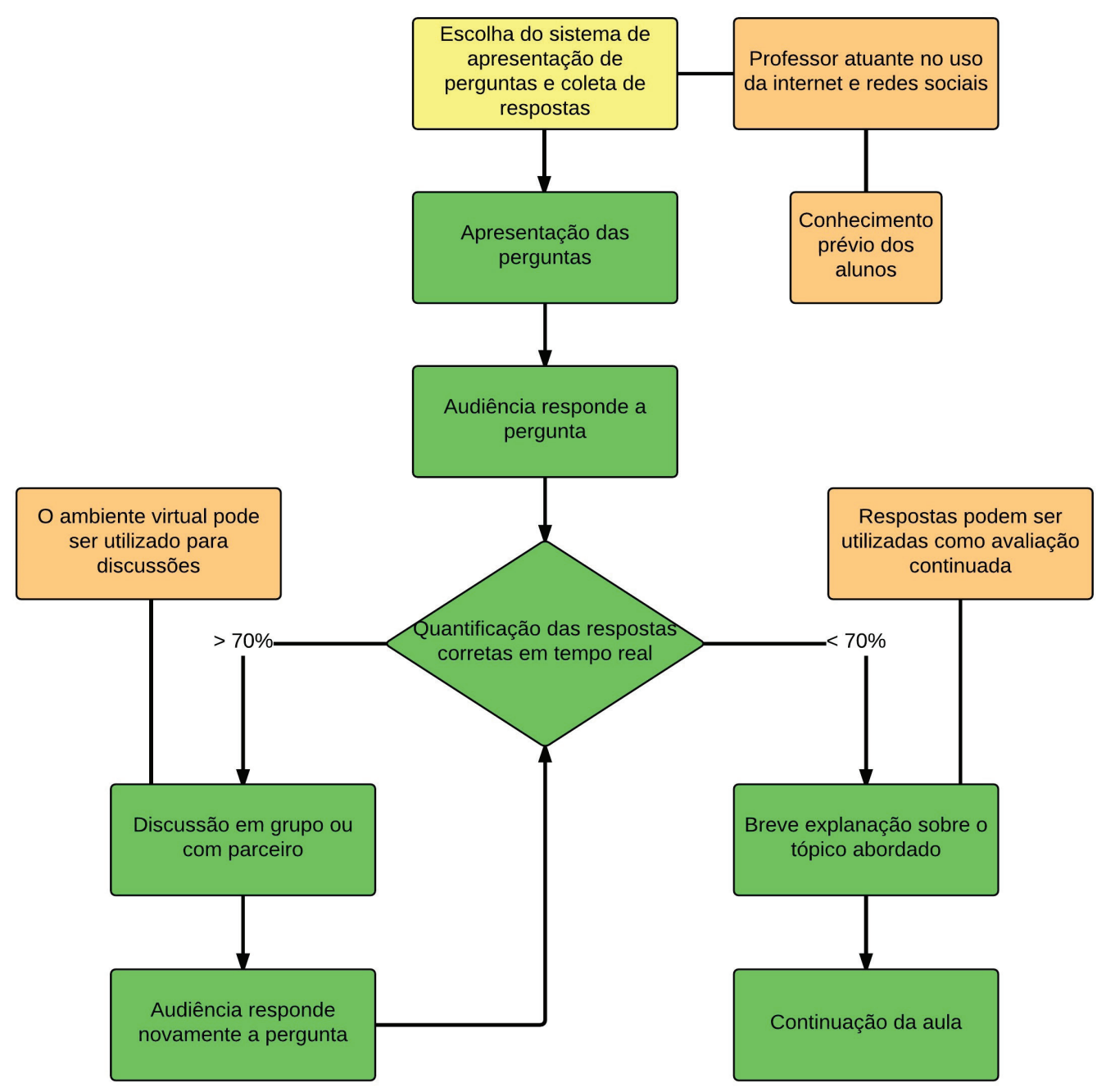

Figura 1 - Fluxograma para a aplicação do peer-instruction. Em verde, aparecem as etapas consideradas tradicionais; em laranja, as partes que auxiliam e aumentam a eficácia do método; em amarelo, ganha destaque o ponto chave deste trabalho.

pode não capturar suficientemente o interesse dos estudantes. Diante disso, a criação de perguntas sobre um determinado tópico pode ser otimizada caso o professor conheça previamente seus alunos e o que estes esperam e/ou gostariam de aprender sobre uma disciplina. Nesse sentido, existem diversas redes sociais e questionários on-line capazes de serem aprimorados para que uma proposta de estudo fundada em exemplos e em conteúdos de amplo interesse possa atingir de modo mais efetivo os estudantes, os quais devem ser conhecidos previamente pelo professor. É nesse contexto que o presente trabalho se insere.

Hoje, sabe-se que as pessoas passam cada vez mais tempo conectadas às redes sociais, interagindo e discutindo os mais variados temas. Em função disso, torna-se cada vez mais necessária a criação de ambientes on-line onde os estudantes sejam encorajados a debater e a buscar outras fontes de conhecimento na internet, o que deve ser mediado pelo professor. Este, por sua vez, deve ter domínio completo acerca do uso das redes sociais preferidas pelos estudantes. Interessante observar neste trabalho, como se menciona a seguir, que o uso das redes sociais propicia um modo adicional de interação socioconstrutivista professor-aluno e aluno-aluno a longa distância (VYGOTSKY, 2012; ANDERSON \& DRON, 2011).

Adicionalmente, a partir de resultados preliminares, detectou-se que o uso frequente e sistemático do PI permite a realização de avaliação continuada de cada estudante ao longo de um semestre. Isso será objeto de análise e discussão futura. 
No que tange ao ponto central deste trabalho (quadro amarelo da Figura 1), é importante mencionar que a aplicação do PI não está necessariamente ligada à utilização de clickers. Em função de todo o desenvolvimento de redes sociais e ferramentas on-line disponíveis atualmente, é possível se valer do PI sem a necessidade de grandes investimentos de tempo pelos professores e de recursos financeiros por parte das instituições de ensino e dos alunos. Porém, é preciso levar em conta que um ponto chave para o emprego do PI diz respeito à escolha do sistema alternativo, que deve ter capacidade de interagir com os estudantes quando eles responderem as questões apresentadas. Leia-se "capacidade" no sentido de que as ferramentas utilizadas precisam ser absolutamente intuitivas para os alunos, algo que se revela ainda mais eficiente caso sejam utilizadas plataformas com as quais eles já estão familiarizados, tais como as redes sociais mais usadas no momento ${ }^{3}$.

Esse é um ponto crucial em que muitos cursos de ensino a distância $(\mathrm{EaD})$ parecem pecar (COLE et al., 2014). De um modo geral, eles possuem sua própria plataforma, sempre repleta dos mais diversos recursos que, entretanto, são de pouco domínio e de baixa interatividade com os alunos. Em sentido oposto, observa-se que grandes empresas cujos produtos atuam diretamente com plataformas on-line, como Google ${ }^{4}$ e Facebook $^{5}$, cada vez mais caminham no sentido de criarem ferramentas com recursos limitados que, por outro lado, apresentam grande apelo à interatividade e à funcionalidade para com seu público-alvo, e contam com suporte de outros sistemas disponíveis na internet.

Dessa maneira, é importante avaliar a capacidade de cada uma das ferramentas propostas no que diz respeito ao público-alvo, isto é, os estudantes devem gostar e se sentir confortáveis com cada sistema adotado. Assim, o presente trabalho demonstra que qualquer rede social pode ser utilizada com sucesso; no entanto, mostra-se fundamental que a rede escolhida seja aquela com que os estudantes estejam mais familiarizados. Tal constatação mostra o quanto é vital para os professores também conhecerem e serem usuários ativos das redes sociais para que esse tipo de atividade interativa tenha sucesso.

Conforme já mencionado, a aplicação do PI em Lorena ocorreu durante dois anos nas disciplinas de Física I e II dos cursos de engenharia. Grupos de trabalho foram criados no Facebook e no WhatsApp ${ }^{6}$ nos quais os alunos eram encorajados a discutir os temas apresentados. Além disso, utilizavam-se ambas as ferramentas durante a aula para a divulgação dos links das questões conceituais a serem respondidas. Por sua vez, empregou-se, ainda, a plataforma Google Forms ${ }^{7}$ para a formulação de perguntas e obtenção de respostas. A partir de tais informações, pôde-se elaborar formulários para estudos estatísticos, os quais forneceram ao professor a quantificação das respostas de seus alunos em tempo real.

\section{O Uso do Facebook}

O Facebook foi a principal plataforma utilizada para a criação de um ambiente voltado à apresentação de materiais adicionais, vídeos e textos, e também para discussão de dúvidas e dos tópicos propostos. Em linhas gerais, a experiência com o Facebook revelou-se muito positiva devido à facilidade e à familiaridade dos estudantes no que concerne à utilização dessa rede social. Nela, mais especificamente, criou-se um grupo fechado, administrado pelo professor, do qual todos os estudantes faziam parte. $\mathrm{Du}^{-}$ rante o semestre, os graduandos foram encorajados a compartilhar materiais adicionais àqueles utilizados pelo docente, e, desse modo, não por acaso, o uso dessa ferramenta facilitou o contato professor-aluno, uma vez que as dúvidas podiam ser sanadas com maior agilidade e com o suporte de qualquer material disponível na rede. Outro ponto importante na utilização do Facebook diz respeito à presença constante de um aluno de pós-graduação vinculado ao Programa de Aperfeiçoamento de Ensino (PAE) ${ }^{8}$, que procurava sanar dúvidas apresentadas, além de trazer outras fontes de materiais, exercícios, vídeos etc. A Figura 2 apresenta uma fotografia de uma aula 
na qual se empregou o Facebook como forma de contato no método PI.

A fotografia apresentada na Figura 2 e o estudo do comportamento coletivo dos alunos durantes as aulas apontam aspectos que são dignos de nota, a saber: i) ao lançar mão de ferramentas on-line e das redes sociais, o professor demonstra aos seus alunos que ele está bastante familiarizado com elas, criando uma forma adicional de diálogo professor-aluno ${ }^{9}$, o que produz um significativo aumento na interação; ii) como os graduandos devem responder às questões, eles ficam atentos a tal ação, deixando em segundo plano o acesso à internet para assuntos não associados ao tema da aula. Assim, é muito comum encontrar diversos alunos dando atenção à tela de projeção ou à lousa, ou discutindo entre si; iii) os discentes atuam ativa e coletivamente durante as aulas, sendo que o problema das respostas serem emitidas por poucos alunos em uma aula tradicional é totalmente eliminado mediante o uso do PI, algo que permite ao professor avaliar em tempo real o aprendizado de um dado tema pela turma; e iv) como os alunos possuem contato com diversos colegas pela rede social, o uso do PI adaptado possibilita a interação aluno-aluno não somente entre os que estão fisicamente próximos, mas também entre aqueles que se interrelacionam virtualmente via Facebook, processo este que ocorre com baixíssimo ruído. Isso foi denominado como interação socioconstrutivista a longa distância (long-distance socioconstrutivism) (VYGOTSKY, 2012; ANDERSON \& DRON, 2011).

\section{O Uso do Google Forms}

O Google Forms possibilita ao usuário criar formulários tendo em vista a realização de pesquisas estatísticas e, por isso, dispõe de uma plataforma preparada e intuitiva para o público responder questões e organizá-las de maneira a facilitar a análise de cada resposta. Esse sistema permite elaborar perguntas que podem ser abertas em qualquer dispositivo eletrônico que possui acesso à internet, e,

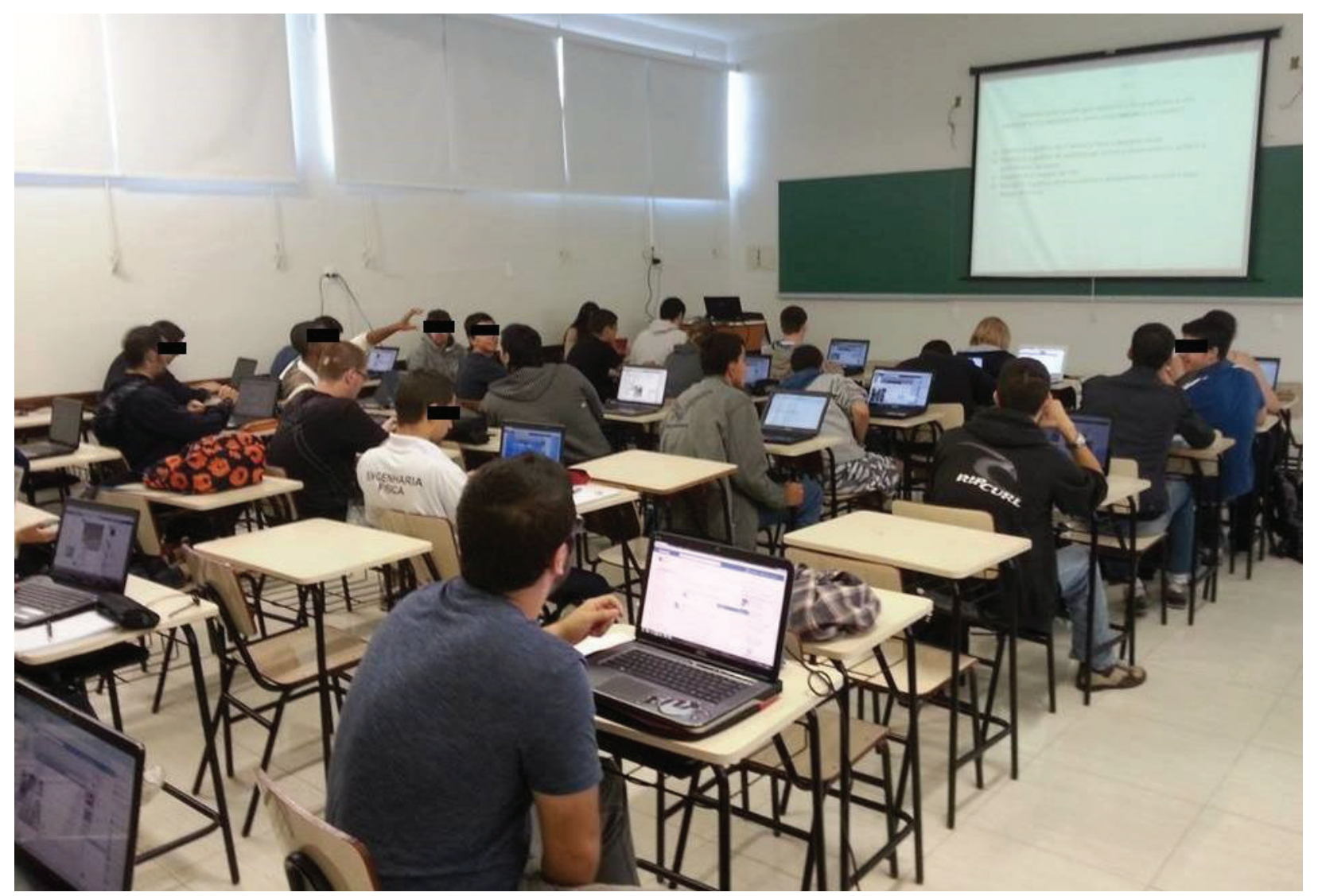

Figura 2 - Fotografia que mostra os alunos interagindo por meio do Facebook durante a discussão de um exercício com o uso do método peer-instruction. É possível observar muitos graduandos olhando para a tela de projeção, alguns discutindo entre si e outros interagindo por meio da rede social. 
por tal motivo, foi utilizado para o propósito da aplicação do PI neste trabalho.

A Figura 3 mostra exemplos de perguntas criadas no Google Forms que foram lançadas para a audiência do $1^{\circ}$ Congresso de Graduação da Universidade de São Paulo, realizado em maio de 2015. Dos presentes ao evento, quarenta pessoas responderam as perguntas durante a apresentação. Como nesse caso não havia conhecimento prévio da audiência, o link com as perguntas foi exibido na forma escrita diretamente nos slides da exposição realizada.

Nas aulas de Física na EEL, os links com as questões, em geral, foram disponibilizados durante as aulas em um dos ambientes de rede social, o que aumentava sensivelmente a agilidade para o acesso às perguntas por parte dos alunos.

A Figura 4 apresenta o resumo das respostas às perguntas lançadas à audiência. A obtenção dos dados e suas análises foram realizadas em tempo real, e mostradas à audiência no final da própria apresentação.

Embora os dados apresentados na Figura 3 sejam de interesse para discussão, como fogem do escopo deste trabalho, não serão analisados, ficando somente menção ao fato de que o professor pode usar os resultados obtidos em tempo real para discutir pontos positivos ou dirimir possíveis divergências ou discussões que mereçam destaque.

Por fim, é necessário chamar alguma atenção às possíveis dificuldades decorrentes do uso do método aqui proposto. Durante os diversos semestres de aplicação dele foi possível observar que a maioria dos estudantes estava engajada

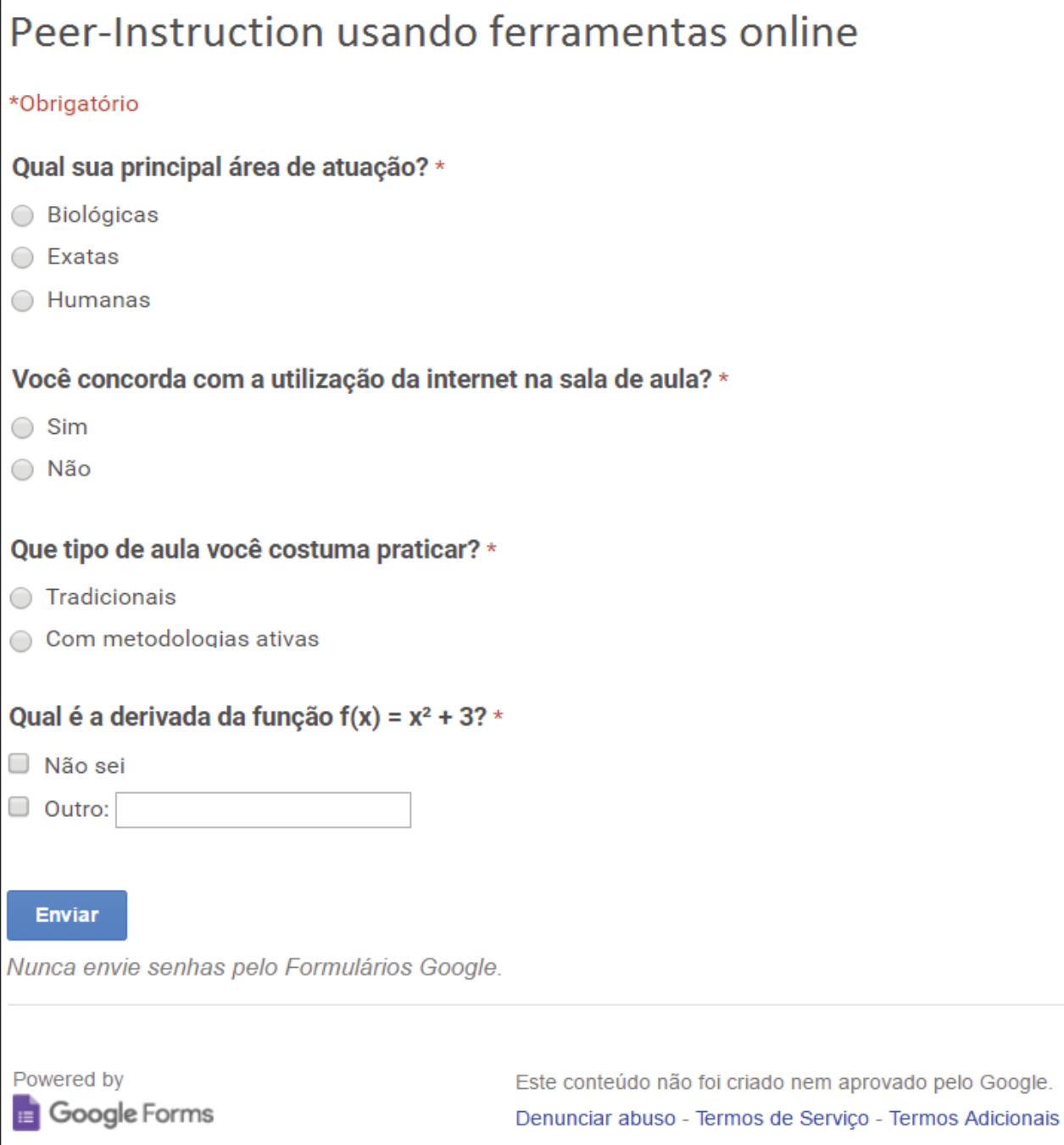

Figura 3 - Perguntas lançadas à audiência durante o $1^{\circ}$ Congresso de Graduação da Universidade de São Paulo (2015). A imagem foi retirada diretamente do Google Forms por meio da impressão da tela. 


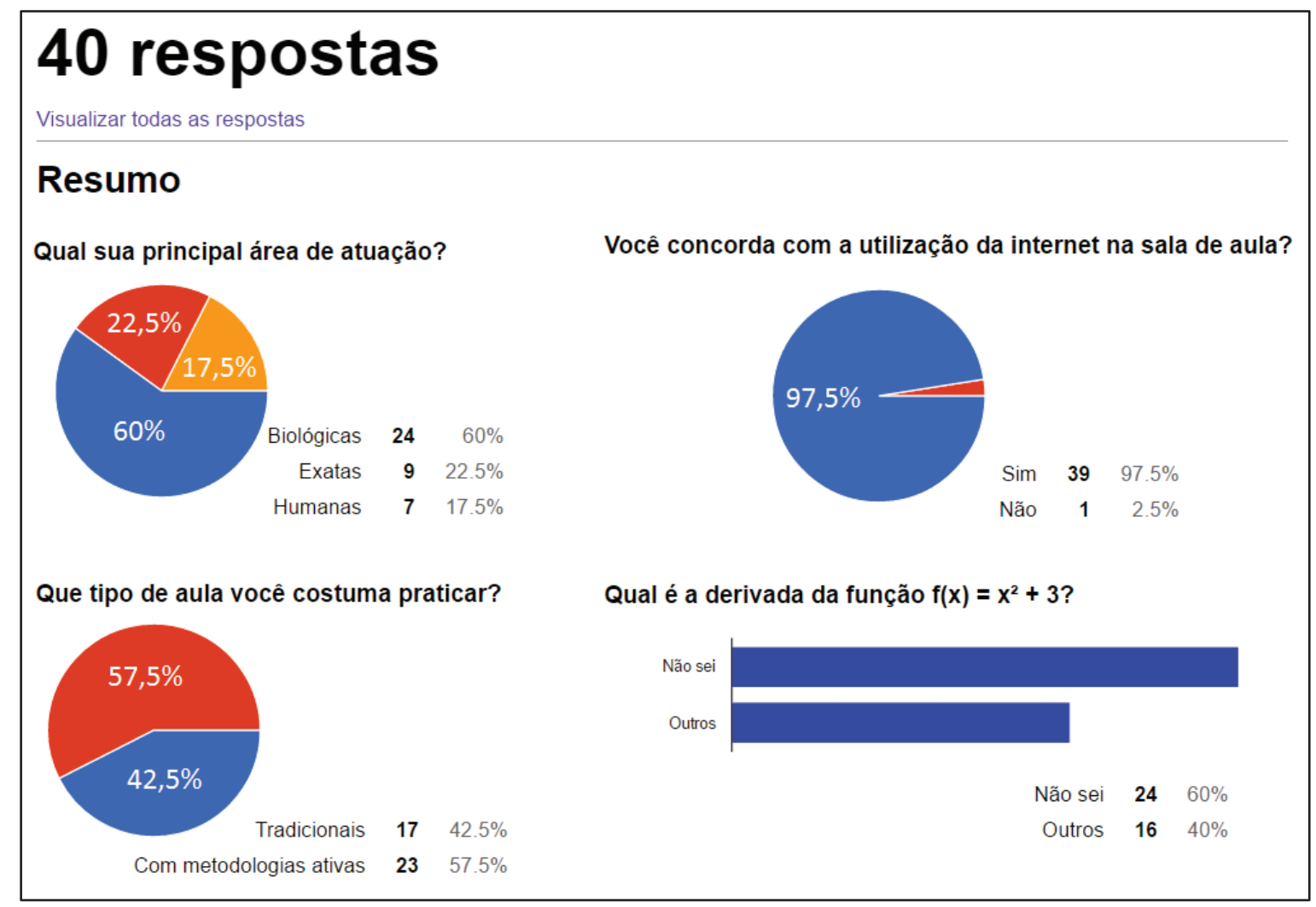

Figura 4 - Dados quantificados obtidos em tempo real das respostas às perguntas apresentadas na Figura 3. A imagem foi retirada diretamente do Google Forms por meio da impressão da tela.

em responder as questões, entretanto, problemas como smartphones ou laptops sem baterias, estudantes que não portavam seus dispositivos ou problemas de acesso à internet variaram de zero a $20 \%$ do total dos alunos presentes nas diversas aulas.

\section{Conclusões}

A partir deste trabalho podem-se inferir as seguintes conclusões:

i) De fato, a metodologia PI propicia a ação ativa dos estudantes nas disciplinas de física dos cursos de engenharia da EEL-USP;

ii) O PI pode ser utilizado em diversas aulas sem prejudicar o conteúdo programático das disciplinas;

iii) $\mathrm{O}$ método alternativo usando ferramentas on-line é simples e não demanda muito conhecimento tecnológico ou a respeito de informática para seu desenvolvimento, sendo, portanto, atrativo para profissionais de todas as áreas do conhecimento;

iv) $\mathrm{O}$ método desenvolvido neste trabalho é atrativo e evita o desvio do foco do aluno para outras ações na internet (há uma espécie de com- petição entre o uso do sistema alternativo com o uso de redes sociais);

v) A metodologia propicia a interação socioconstrutivista entre alunos a distância por meio de rede social, além daquela tradicional;

vi) É imperativo que os professores saibam que há questões de habilidades e competências transversais que precisam ser avaliadas cuidadosamente antes e ao longo do semestre, além daquelas vinculadas ao uso do método PI por si só; e

vii) Resultados preliminares (não apresentados) sugerem que o PI pode ser usado para a realização de avaliação continuada.

\section{Agradecimentos}

Este trabalho foi apoiado pelo Programa de Aperfeiçoamento de Ensino (PAE) da PRPG-USP e pelo Programa Novos Talentos da CAPES (Proc. 23038.004534/2013-14).

\section{Notas}

1. Um exemplo de clicker pago vinculado a smartphones é o i>clicker, disponível em <https://www1.iclicker.com/ $>$. Acessado em 21 jun. 2016. 
2. Dado obtido do site Statista, disponível em <http:// www.statista.com/statistics/220977/global-smartphone-market-share-forecast-by-country $>$. Acessado em 21 jun. 2016.

3. No momento de elaboração deste texto, as redes sociais mais utilizadas pelos estudantes eram o Facebook, o WhatsApp e a plataforma do Google.

4. Disponível em <http://www.google.com>. Acessado em 21 jun. 2016.

5. Disponível em <https://www.facebook.com>. Acessado em 21 jun. 2016.

6. Disponível em <https://www.whatsapp.com>. Acessado em 21 jun. 2016.

7. Disponível em <https://www.google.com/forms/ about $>$. Acessado em 21 jun. 2016.

8. Informações sobre PAE estão disponíveis em $<$ http://www.prpg.usp.br/index.php/pt-br/pae/oque-pae $>$. Acessado em 21 jun. 2016.

9. Interação muito comum em atividades de ensino a distância $(\mathrm{EaD})$.

\section{Referências Bibliográficas}

ANDERSON, Terry \& DRON. Jon. "Three Generations of Distance Education Pedagogy". The International Review of Research in Open and Distributed
Learning, vol. 12, n. 3, 2011.

COLE, Michele T.; SHELLEY, D. J.; SWARTZ, L. B. "Online Instruction, E-learning, and Student Satisfaction: A Three Year Study". The International Review of Research in Open and Distributed Learning, vol. 15, 2014.

CROUCH, Catherine H.; MAZUR, Eric. "Peer-instruction: Ten Years of Experience and Results". American Journal of Physics, vol. 69, n. 9, set. 2001, pp. 970-977.

FAZENDA, Ivani Catarina Arantes. Dicionário em Construção: Interdisciplinaridade. São Paulo: Cortez, 2001.

LASRY, Nathaniel. "Clickers or Flashcards: Is There Really a Difference?". The Physics Teach. vol. 46, n. 4, 2008, p. 242-244.

MAZUR, Eric. Peer-instruction: A User's Manual. Harlow, Essex: Pearson Education, 2013.

MOURA, Bruna Ligabo de. Aplicação do Peer-instruction no Ensino de Matemática e Ciências Exatas para Alunos de Quinto Ano do Ensino Fundamental. Dissertação (Mestrado Profissional em Projetos Educacionais de Ciências), Escola de Engenharia de Lorena, Universidade de São Paulo, 2016.

VYGOTSKY, Lev Semenovich. Thought and Language. Cambridge, MA: MIT Press, 2012.

Publicado em 05/07/2016. 